\title{
A EDUCAÇÃO A DISTÂNCIA NO ENSINO SUPERIOR: UM PARADIGMA DE ENSINO NA CONTEMPORANEIDADE
}

\author{
DISTANCE EDUCATION IN HIGHER EDUCATION: A PARADIGM OF EDUCATION \\ IN CONTEMPORANEITY
}

\author{
Josué Teixeira de Abreu Neto ${ }^{1}$ \\ Marcel Pereira Pordeus ${ }^{2}$ \\ Carlos Henrique Gomes da Silva ${ }^{3}$
}

RESUMO: O presente artigo é um recorte da minha dissertação de mestrado realizado no exterior, em que apresento a relação da Educação a Distância (EAD) em nível superior no Brasil. Desse modo, vem sendo revelado um novo paradigma de ensino significando uma nova tendência em toda a esfera educacional, especialmente no que diz respeito a educação superior. Para a construção desse trabalho foram utilizadas as bases de pesquisa Lilacs, Scielo, dentre outras, a partir de critérios de inclusão/exclusão recuperados e analisados através de teses, dissertações e artigos científicos que abordam o assunto. Contanto, iremos apresentar apenas teorias inerentes à temática, em seu recorte sincrônico. O material utilizado para a demonstra que essa modalidade de ensino já não é mais uma novidade que envolve o mundo educacional, por sua vez foi identificado através de registros que a sua primeira utilização ocorreu no ano de 1728. Para dar luz ao tema, procurou-se debater os aspectos relevantes à educação, tais como mobilidade social, legislação da EAD no Brasil, a relação do professor com o aluno e os métodos de ensino com foco na auto formação, baseado nos teóricos como Belloni (1999), Tuckma (2005), Batista (2006) dentre outros. Apresentando assim, a compreensão que a EAD demonstra como uma ferramenta essencial para a otimização do processo de ensino aprendizagem e para a redução das desigualdades das oportunidades escolares.

Palavras-chave: Educação à Distância (EAD). Ensino Superior (ES).

ABSTRACT: This paper is an excerpt from my master's thesis carried out abroad, in which I present the list of Distance Education (EAD) at a higher level in Brazil. In this way, a new teaching paradigm has been revealed, signifying a new trend in the entire educational sphere, especially with regard to higher education. For the construction of this work, the research bases

\footnotetext{
1 Mestre em Ciências da Educação pela Universidad Interamericana. Professor da Educação Básica e Educação de Jovens e Adultos na Prefeitura Municipal de Fortaleza. E-mail: abreuresponder@gmail.com.

${ }^{2}$ Mestrando em Planejamento e Políticas Públicas pela Universidade Estadual do Ceará (UECE) - Graduado em Letras: Português/Literaturas pela Universidade Federal do Ceará- UFC. E-mail: marcel.pordeus@aluno.uece.br.

3 Graduado em Direito pela Universidade Estácio de Sá. Graduando em Licenciatura em História pela Universidade Estácio de Sá. Graduando em Licenciatura em Artes Visuais pela Universidade Estadual do Ceará. MBA em Gestão Fiscal e Tributária pela Universidade Estácio de Sá. Especializando em Direito Tributário pela Pontifícia Universidade Católica de Minas Gerais. E-mail: contato@drcarloshenrique.adv.br.
} 
Lilacs, Scielo, among others, were used, based on inclusion / exclusion criteria retrieved and analyzed through theses, dissertations and scientific papers that address the subject. However, we will only present theories inherent to the theme, in their synchronic cut. The material used for the demonstration shows that this teaching modality is no longer a novelty that involves the educational world, in turn it was identified through records that its first use occurred in the year 1728. To give light to the theme, we sought to discuss aspects relevant to education, such as social mobility, distance education legislation in Brazil, the relationship between the teacher and the student and teaching methods focusing on self-training, based on theorists such as Belloni (1999), Tuckma (2005), Batista (2006) among others. Thus presenting, the understanding that EAD demonstrates as an essential tool for the optimization of the teaching-learning process and for the reduction of inequalities in school opportunities.

Keywords: Distance Education (EAD). Higher Education (ES).

\section{INTRODUÇÃO}

O presente estudo foi elaborado por meio de uma revisão bibliográfica integrativa, contanto, nos delimitamos nesse recorte em apenas apresentar uma versão sincrônica dos dados auferidos, onde foi realizada uma pesquisa analítica sobre a oferta de ensino na modalidade de educação a distância, no âmbito do ensino brasileiro. Nos últimos vinte anos a Educação a Distância (EAD) tem sofrido diversas modificações em quase todo o mundo. Visto que essa modalidade educacional, na atualidade, ocorre por intermédio do uso de meios tecnológicos de informação e comunicação, onde alunos e professores desenvolvem atividades educativas, em vários lugares e a qualquer momento por meio da tecnologia. A modalidade de ensino a distância é constituída de ferramentas que de forma concomitante, permitem que os integrantes possam interagir e compartilhar em tempo real, chats e assíncronas, contudo, não se mantém em tempo real igual aos fóruns e seminários. E tudo isso com a finalidade de desenvolver o conhecimento entre as pessoas que estão separadas fisicamente (PEREIRA, 2007).

Essa modalidade de ensino teve seu início no Brasil marcado pelos cursos livres e técnicos, funcionando assim, como uma inovação, imprescindíveis para que o capitalismo pudesse renovar-se e ampliar sua margem de riqueza, tendo como princípio a base industrial consolidada. Porém, atualmente o seu grande desenvolvimento está nos cursos de Ensino Superior (ES), sejam de graduação, pós-graduação Lato Sensu e Stricto Sensu, principalmente, após o Artigo 87 , § 4º da Lei de Diretrizes e Bases da Educação Nacional 939496 (LDBEN), a qual ressalta que somente serão admitidos professores com formação superior ou em formação em andamento, durante o exercício legal da profissão.

Neste sentido, foi criado pelo Ministério da Educação (MEC) um número de mais de sete mil vagas, principalmente para atender a demanda de formação de professores e suprir essa necessidade. Foi criado um programa de pró-licenciatura, no qual teve por objetivo ofertar diversos 
cursos de licenciatura voltados para professores da rede pública que atuam na docência no Ensino Fundamental e Médio (EFM). Nas últimas décadas foi possível perceber de maneira positiva a expansão dessa modalidade por colaborar para ampliação do acesso da população ao Ensino Superior, desse modo, se antepondo diante as formalidades do ensino convencional, já que por sua vez, a EAD permitiu a democratização ao acesso à educação.

Em 2005 o MEC criou a Universidade Aberta do Brasil (UAB) que teve a finalidade de ampliar e qualificar de maneira mais coordenada os projetos em EAD, que por sua vez tem duplicado os esforços no intuito de avaliar, analisar os cursos de EAD que são ofertados por todo Brasil.

Segundo o MEC/CAPES, o Programa UAB se sustenta em cinco eixos que são essenciais: ampliação pública da educação superior, levando em consideração os processos de acesso e democratização; aprimoramento dos métodos de gestão das instituições de ES, propiciando sua expansão em concordância com as propostas educacionais dos estados e municípios; avaliação do ensino superior à distância, baseado nos processos de flexibilização e regulamentação estabelecidos pelo MEC; incentivo à investigação em educação superior a distância no País; financiamento dos processos de implantação, formação e realização de recursos humanos em educação superior à distância.

Essas definições dos programas da EAD complementam-se com o primeiro parágrafo do mesmo artigo, onde é ressaltado que esta deve ter obrigatoriamente momentos presenciais, como se segue no కI$^{\circ}$ : A EAD organiza-se segundo metodologia, gestão e avaliação peculiares, para as quais deverá estar prevista a obrigatoriedade de momentos presenciais para: I - avaliações de estudantes; II - estágios obrigatórios, quando previstos na legislação pertinente; III - defesa de trabalhos de conclusão de curso, quando previstos na legislação pertinente e IV - atividades relacionadas a laboratórios de ensino, quando for o caso (BRASIL, 2005).

Deste modo, no contexto da contemporaneidade, pode-se dizer que a EAD se faz necessária em um mundo que se mostra pequeno à medida que se intensifica o rápido acesso a qualquer informação, em qualquer lugar do mundo. Contudo, se faz necessário a verificação das legislações formuladas nesse cenário dentre outros documentos oficiais, a fim de deixar claro suas conformidades e não conformidades diante da instituição de educação.

Atualmente, a comunicação internacional torna-se um ato corriqueiro, assim, o desenvolvimento, aprimoramento e consolidação de uma educação a distância nacional de qualidade e próprio da nossa cibercultura é uma demanda dos nativos digitais. Assim, cria-se uma era para a educação a distância que por muito tempo carregou o estigma de ensino de segunda categoria; isso refletindo o fato de que durante parte considerável de sua história seus objetivos 
estiveram voltados prioritariamente para a educação de adultos. Diante desse contexto, se presume que deva existir problemas no âmbito do ensino a distância. Visto que a compreensão do problema é indispensável para investigação. Define-se aquilo que se pretende estudar. Formula-se um problema que seja exequível de ser investigado, pertinente e que tenha interesse e relevância, valor teórico, significado prático e amplitude crítica (TUCKMA, 2005).

\section{A CIBERCULTURA NO CONTEXTO DE ENSINO A DISTÂNCIA}

Na cibercultura existem muitas áreas, contudo a que mais se destaca é o ciberespaço. É um espaço de comunicação onde não necessita do homem físico para gerar uma interação como forma de relacionamento, e que foram obrigados a modificar e a agregar como objeto de estudo se beneficiando com as novas tecnologias. Diante desse novo ambiente, se desenvolveu uma nova forma de expressão onde trouxe mais velocidade, com trocas de mensagens e informações mais rápidas, sendo um espaço menos formal, realçando o uso da imaginação sendo essa essencial para a geração de uma imagem anônima, que terá união aos demais no âmbito do processo de aprendizagem, de maneira que ocorra uma junção com as criações humanas e a necessidade de aquisição de conhecimento (DOS SANTOS; DE FREITAS, 2016).

A educação formal se estabelece como uma instituição estruturada e organizada, por meio da implantação das novas tecnologias, diante da cibercultura, que vem se deslocando por um período de mudanças e reconstruções. Contudo, é importante destacar que essas transformações não são atuais, uma vez que as tecnologias mencionadas envolvem desde o livro a web-conferência. Procurando assim, ajudar de maneira benéfica o processo de aprendizagem e o desenvolvimento das oportunidades de co-criação do espaço escolar.

Com relação as vantagens que a tecnologia pode propiciar aos alunos da $\mathrm{EAD}$, de maneira que o processo de ensino-aprendizagem seja facilitado, é possível citar as melhorias que a cada dia tem estado presente nos Ambientes Virtuais de Aprendizagem (AVA), favorecendo a troca de relatos e experiências entre alunos e professores. Esses profissionais têm a oportunidade de elaborar fóruns, debates, trabalhos em grupo etc., de modo a estimular o uso das TIC, tornando a aprendizagem uma experiência mais significativa. Segundo Moran (2010 p. 03), “[...] o futuro será aprender em qualquer tempo e lugar, de forma personalizada e, ao mesmo tempo, colaborativa e com flexibilidade curricular, no quadro de um novo conceito de "estarmos juntos", conectados virtualmente".

A educação à distância é uma das áreas no âmbito da educação formal que é mais favorecida, isso porque estabelece técnicas de ensino que incluem as hipermídias, as mais diversas 
redes de comunicação interativas e todas as tecnologias intelectuais da cibercultura. Busca utilizar os mais variados meios para tornar o aprendizado mais fácil, dinâmico e vantajoso, gerando a possibilidade para que as pessoas se organizem a fim de realizarem suas atividades em um mesmo período de sua vida, já que é possível manter uma relação harmoniosa entre o emprego, as atividades domésticas, o lazer e os estudos, pois com a modernidade no mundo tornou-se cada vez mais necessário a boa utilização do tempo. (BARRETO, 2014).

Para esse novo grupo de discentes também surge a necessidade de se estabelecer uma nova pedagogia que favorece ao mesmo tempo as aprendizagens personalizadas e a aprendizagem coletiva em rede, para uma nova docência: o ensino online. Ao mudar o paradigma educacional, carece de mudar as pedagogias para que o professor possa atuar estando preparado, devendo estar preparados para trabalhar como facilitadores, tutores e até mesmo provocadores de participação. Porquanto, fazer uso das interfaces tecnológicas, pedagogicamente, requer uma formação continuada e atualizada constantemente. Ao propor o conhecimento na forma de hipertexto os sujeitos do processo, professor e aluno, atuarão com autonomia e de forma colaborativa.

Em um cenário educacional que não se norteia apenas pela transmissão de conhecimento e, sim, pela orientação na busca do conhecimento, o professor deve potencializar o aluno a estipular metas, planejar e ficar atento para os recursos aos quais estejam disponíveis para o seu fazer profissional. Assim, também é tarefa do professor elaborar o planejamento do curso e a preparação dos recursos didáticos, que devem estar disponíveis para a aprendizagem dos alunos, garantindo assim a uniformidade nas informações a serem disseminadas (ARGUELLO, 2015).

Dentre os recursos didáticos que as novas metodologias da EAD, a partir dos recursos que as ferramentas tecnológicas no processo ensino-aprendizagem permitem para a fomentação dos recursos didáticos, bem como para auxiliar na inclusão digital, a fim de possibilitar o compartilhamento de informações e experiências entre os educandos, pode-se citar: o chat, fórum de discussão, weblog, correio eletrônico, videoconferência, Podcast e vodcast, simuladores e jogos, webcast, wiki, imagens e fotos.

O chat, que em português significa conversação ou bate-papo, é uma ferramenta que por meio da utilização da internet, possibilita ao usuário a conversação de maneira simultânea. Esse uso acontece em ambientes remotos, por meio de mensagens escritas, que são enviadas de maneira particular ou em grupo entre os participantes. Já com relação a EAD, o chat oferece uma gama de oportunidades onde permite que os alunos troquem ideias, solucionem dúvidas acerca do conteúdo das atividades, compartilhem materiais, dentre outros procedimentos. No entanto, esse mecanismo pode desmotivar e/ou se desviar do objetivo pretendido, visto que esse recurso não possui nenhum tipo de controle acerca do assunto que será discutido, e diante disso, pode ser que alguns estudantes 
acabem perdendo o estímulo em participar da discussão, e se desviem do foco principal do debate (BRITO [s.d.]).

Nesse cenário, é de suma importância a presença do professor/tutor para que se tenha um melhor aproveitamento desse recurso, ele tem o papel de identificar com que frequência os alunos participam do chat, incentivando a utilização de maneira sadia e proveitosa, promovendo atividades e questões que impulsione o compartilhamento de opiniões. Um outro fator bastante relevante é com relação ao armazenamento das conversas realizadas, possibilitando ao estudante que não participou do chat ter a chance de ver o que fora discutido, ou que algum assunto possa ser examinado posteriormente por algum aluno.

A respeito do fórum de discussão é um dispositivo virtual, assíncrona que tem por objetivo a promoção de debates entre os participantes, através da publicação de mensagens na página, no qual são abordados determinados assuntos, por meio da introdução de ideias, reflexões e sugestões, com a finalidade de promover a troca de experiências e conhecimentos. Um fórum pode ser classificado de acordo com assunto e as mensagens associadas ao mesmo, ficando de maneira organizada e de modo hierárquico, facilitando na identificação e sequência dos debates e assuntos (FISCHER, 2000).

A utilização do fórum na EAD, é muito importante pois é um instrumento de diálogo que proporciona ao aluno um espaço de aprendizagem individual e coletiva onde gera a oportunidade para os estudantes compartilharem suas opiniões com relação a um determinado tema, contribuindo com o aprendizado de todos. Tal recurso contêm uma interface que é capaz de fomentar a comunicação e a distribuição de ideias. Ou seja, essa ferramenta é bastante utilizada em cursos na modalidade a distância, tendo o objetivo de favorecer a interação entre alunos e professores (SILVA, 2003).

O Weblog ou popularmente chamado de blog, é um outro dispositivo bastante importante e usado, pode ser definido como uma página interativa que, por meio da conexão à internet, possibilita a publicação de artigos, ilustrações, notícias, informações etc., visto que o principal objetivo é proporcionar aos leitores e escritores a distribuição de conhecimentos e experiências, através da interação entre os participantes. Essas publicações, conhecidas como post, são ordenadas cronologicamente, onde a postagem mais recente acaba contendo maior destaque, ao ser exibida no topo da página. Uma importante característica do blog é que ele é um meio de comunicação assíncrono, ou seja, possibilita que os usuários realizem comentários as postagens, promovendo a comunicação entre o escritor e o público, definindo assim o blog como uma considerável ferramenta de mídia social, a qual permite a geração de grupos de participantes que dividem interesses em comum. 
No âmbito dos cursos EAD, é notório que a utilização do método facilita no processo ensino-aprendizagem, possibilitando a conversação entre os participantes, motivando a transmissão de informações que, quando publicadas, analisadas e compartilhadas, poderão ampliar e promover a autonomia desses participantes. O blog também oferta muitas opções de atividades, tanto para o aluno quanto ao professor/tutor, criando um intercâmbio entre instituições educacionais, a fim de discutir assuntos, opiniões, ideias, colaborando com a produção da escrita e da leitura, além de ajudar na formação de estudantes aptos em aprimorar seus conhecimentos. Dentre os objetivos do uso desse instrumento na educação a distância, pondera-se a formação do conhecimento de maneira colaborativa; estimulo à comunicação através da escrita e da leitura; e, desenvolvimento da habilidade de interação entre os usuários (GONÇALVES, 2007).

O Correio eletrônico, mais conhecido como e-mail, é de fato, um dos serviços mais utilizados na internet, sendo que através deste é possível o envio de arquivos anexados em vários formatos, como em texto, imagem, áudio e vídeo, para qualquer pessoa do mundo. Por meio do email houve um grande impacto nas relações de comunicação com redução de custos e aumento da velocidade na transmissão de informações. Desse modo, o seu uso se tornou popular nas mais diferentes esferas e com os mais diferentes propósitos, sendo uma ferramenta assíncrona de utilização para envio de mensagens e documentos importantes de maneira simples e com ampla rapidez.

O e-mail exerce papel essencial na $\mathrm{EAD}$, pois ele colabora com a comunicação entre alunos e professores/tutores, envolvendo de um modo geral, todos que fazem parte do curso e/ou com a coordenação do ambiente virtual, possibilitando a geração de questionamentos, sugestões e comentários. Contudo, a sua utilização requer cuidado, uma vez que pode ocasionar desmotivação no aluno, caso não sejam observados determinados aspectos, tais como o tempo de resposta; a sobrecarga do professor; a sistematização de questões e respostas (ROMANI; ROCHA, 200I).

É possível com essa ferramenta, estruturar um curso de EAD completo, desde a inscrição do estudante até o envio e recebimento de atividades como também o fornecimento de conteúdo, bem como a criação de textos no qual o professor pode conduzir a sua elaboração. Sendo que todas as versões antecedentes do texto, juntos as correções indicadas, continuam armazenadas, de modo que podem ser utilizadas como histórico, envio de textos ou então de outros materiais. O professor pode encaminhar também, por via e-mail, à turma um artigo para leitura ou análise. De acordo com isso, existe a chance de ser desenvolvido um debate acerca do mesmo, fazendo a utilização de uma ferramenta direta como por exemplo o chat ou o fórum de discussão, com a finalidade de incentivar a interatividade entre os estudantes. Existe outros recursos como o canal de comunicação onde alunos e professores podem usar de maneira individualizada ou em grupo, para 
marcar reuniões, trocar informações, esclarecer dúvidas, dentre outros, construção de uma lista de discussão e debate para a turma.

A videoconferência, é considerada um mecanismo de interação síncrona, possibilitando entre os participantes, a interação por meio de duas vias, consentindo na $\mathrm{EAD}$, que o processo ensino-aprendizagem aconteça em tempo real (online), uma vez que as pessoas conseguem se ver e se ouvir simultaneamente. Por meio das ferramentas didáticas disponibilizadas nesse ambiente, na medida em que o professor esclarece uma determinada definição, ele pode adicionar outros métodos pedagógicos, como gráficos, slides, projeção de vídeos, imagens, arquivos de computador etc., (CRUZ; BARCIA, 200o). Esse mecanismo também permite que o estudante, ao mesmo tempo que acontece a apresentação, tire suas dúvidas, interagindo junto ao professor. Dessa maneira, é possível verificar que a videoconferência é uma tecnologia que oferece a grupos que estão geograficamente distantes a se comunicarem através de sinais de áudio e vídeo. Essa transmissão pode ocorrer tanto por via satélite como também por linhas telefônicas

Cyrs e Conway (1997, p. 23) mencionam algumas competências que o professor/tutor precisa desenvolver, a fim de fazer uso da videoconferência em suas aulas:

\section{A INOVAÇÃO TECNOLÓGICA NO ENSINO À DISTÂNCIA}

A utilização das tecnologias no ensino formal torna-se uma prática cada vez mais corriqueira na atualidade, e, ao contrário do que muitos pensam, essa não é uma prática recente na nossa sociedade, seja ela na educação presencial ou na EAD. Com o advento dos quadros interativos e a presença dos computadores portáteis na sala de aula, surgiram contratações expressivas nos formatos de transmitir e de adquirir conhecimentos. Contudo, na atualidade, tem se intensificado a variedade de artifícios modernos com o intuito de fomentar os estudos nos âmbitos escolares (GOMES, 2003).

Portanto, em se tratando de educação à distância o protagonismo das tecnologias se faz necessário, mas às vezes, pode também surgir a problemática de enfretamento de determinados pontos a serem discutidos em relação a questão da desigualdade cultural dos educandos, por contadas dificuldades de acesso e apreensão ao sistema. Todavia, é de costume se destacar que as inovações tecnológicas devam afetam todos os domínios da coletividade, enquanto na prática não

observamos isto. É certa que, a necessidade de renovação é uma demanda do capital e a inovação acontece conforme as perspectivas dos autores do capital (DE ALMEIDA, 2003).

A partir da compreensão dos que defendem a função da educação também nos procedimentos de mudança dos modelos culturais e de métodos sociais, esses novos paradigmas 
decorrem não somente num intercâmbio da informação, mas de técnicas de ensino, de novas configurações de aprendizado e até de regras e estima da cultura na qual está colocada a EAD. Tendo, portanto, o intuito de colaborar para o progresso através de uma melhor propriedade da educação oferecida por nossos estabelecimentos educativos, suscitando uma sinergia de caráter prático entre as construções sociais e a educação formal.

Deste modo, as inovações educacionais determinadas pela EAD (técnicas, metodologia, organização) acabam por influenciar positivamente toda a sociedade, no processo de dialética, onde a sociedade influencia o estudo, e este influencia a sociedade no ensino presencial, portanto, não ficando de fora desse intercambio a gênese inicial e continuada dos processos da educação formal. Contribuindo para a formação de uma nova construção do aparelho social que influencia na comunicação e no entendimento a respeito da conduta inovadora, que se caracterizam por seu espírito ousado, seus métodos criativos que não temem em arriscar em novos eventos e de acolher a ideia de passar por riscos para a realização de um novo feitio.

A acessibilidade segura e com preços de baixo valor monetário para à classe baixa, faz à banda larga de internet como uma condição de popularização do ensino a distância. E ainda, como programas que cobrem as necessidades principais dos aparelhamentos, assim, não existirão desiguais níveis de capacidade dentro da mesma classe virtual. Além disso, o estudante conta com o auxílio dos tutores aos quais competirão associar todos os estudantes.

É notório que o estudante da EAD precisa de muita autonomia e capacidade de adaptação ao novo, além de um pré-conhecimento de informática para estar em consonância com os principais constitutivos da aprendizagem aberta, que são: flexibilidade e liberdade do aluno (time free, place free, pace free) e oferta voltada para as instâncias do aluno, ou seja, flexibilização acessível e das metodologias de instrução e de avaliação (BELLONI, 1999).

O sistema EAD é inovador, sendo considerado o pioneiro na adoção de modernas opiniões em nosso aparelho social, por conta de suas metodologias e seu status social ou estado financeiro, que consiste, geralmente, por membros da minoria e está entre a convergência dos dois 'paradigmas' de ensino (presencial e a distância), que se formulam em consequência de modificações sociais, especialmente no negócio de trabalho e, por outro, é o mentor da coerência das TIC à vida habitual e aos processos culturais e comunicacionais, designando modernas necessidades e ações educativas e determinando novos costumes de constituir e oferecer a educação formal.

Embora, a maior parte das instituições educacionais demore a adotar as inovações tecnológicas, passando a constituí-las somente por coação do sistema ou por necessidade econômica, esse ato se apresenta como uma estratégia de economia e ganho de lucro, pois as 
tecnologias só são adotadas quando as inseguranças das novas tecnologias forem rejeitadas, pois somente assim a maior parte das instituições passa a adotá-las, havendo ainda aquelas que só adotam depois que as invenções já se constituíram como um sucesso no mundo da educação a distância.

A inovação, neste âmbito, não fica restrita somente ao ambiente acadêmico e faz referência aos desígnios dos autores envolvidos e suas percepções teóricas da coisa. Neste conjunto mundial, a EAD surge como uma modalidade de oferta de ensino que acolhe às questões do mercado, satisfazendo, deste modo, à dialética do capitalismo moderno (globalização, eliminação, unificação e padrão cultural), contudo como uma nova maneira de ingresso na educação, igualmente apropriado às ambições e peculiares das diversas clientelas, principalmente as mais jovens.

Outro ponto merecedor é o questionamento de que se as inovações necessitariam chegar através do ensinamento ou pela prática, pela educação ou pela observação, pelas mudanças nas maneiras dos educandos ou dos tutores, por consignações colocadas em instituições públicas e oficiais, ou não. Do mesmo modo, a dimensão da análise a respeito do que é inovado no ensino, incide sobre os domínios municipal, estadual, regional, nacional, EF, EM, Técnico ou Superior. Sendo a última dimensão o questionamento por que se inova (GATTI, 2013).

Nesse contexto, é importante enfatizar a necessidade do modelo econômico, além da obtenção de uma política estrangeira, da legislação e de pesquisas. Estas mudanças que ocorrem no processo econômico, na operacionalização e gestão do trabalho, na elevação no mercado de empregatício e de consumo, e também nos costumes culturais que cada vez mais são propagados através da mídia, e evidentemente, requerem mudanças nas normas de ensino, estabelecendo desafios atuais, renovação no que diz respeito no desígnios e fundamentos sociais e em consequência, das estratégias, de maneira que responda as questões educacionais atuais, essencialmente com a entrada de componentes técnicos e de uma flexibilidade crescente quanto aos currículos e os recursos de ensino à distância (BATISTA, 2006).

Outro ponto importante, é com relação a grande intensidade com que os princípios atuais da educação ressaltam o crescimento das novidades tecnológicas, que foram criados por meio da necessidade de extensão das forças produtivas no sistema capitalista. Outras na elaboração de novas descobertas e invenções, na geração de meios técnicos que posteriormente irão governar e incentivar o desenvolvimento industrial e, assim a elevação da produtividade com o objetivo de atender as demandas que possam acelerar o processo de aprendizagem da sociedade atual. 


\section{CONSIDERAÇÕES FINAIS}

A tão esperada transformação no sistema educacional demanda a necessidade de partir da ressignificação de definições como cooperação, emancipação e eficiência, tais conceitos que são utilizados para agilizar processos de mudança que atualmente estão apoiados em concepções imediatistas relacionadas à lógica empresarial capitalista. Nesta linha de raciocínio, o ato de cooperar que deveria estar conectado a uma prática coletiva formada por meio da análise da realidade, de seus conflitos e da construção de alternativas, está vinculado à realização de tarefas. A emancipação dos sujeitos é uma estruturação que tem início no processo de autonomização dos grupos que, pela a prática ético-político de suas ações, criam sentidos comuns para seu fazer.

Tendo em vista os avanços que a modalidade à distância pode trazer para a educação, percebe-se neste estudo a necessidade de acompanhar esta evolução e tentar melhorar cada vez mais os recursos e estratégias que a compõem. Portanto, é notório a importância das tecnologias da informação e que ainda não foram plenamente consideradas dentro do contexto da educação. No que concerne a evolução da $\mathrm{EAD}$, entende-se que ainda carrega muitos vestígios da presencial, um forte exemplo disso é o papel de destaque que se dá ao tutor, ato esse que pode atrapalhar a evolução das metodologias, uma vez que a educação a distância foi criada como forma de ampliação do acesso e decorrente democratização, sendo este o primeiro trabalho sobre inclusão. Um desafio seria tomá-lo como base para uma pesquisa empírica que analisasse na prática, sob vários ângulos o trabalho do tutor no Brasil. Não que os trabalhos dos tutores sejam dispensáveis ou insuficientes, ao contrário, em virtude da sua riqueza, sugere novas janelas para o prosseguimento do fluxo de investigações e construções de novos conceitos. Porém, o educando precisa criar formas de trabalhar a construção do pensamento crítico através de um processo contínuo, processual e menos mediado e mais autônomo.

O ensino online pode favorecer ao estudante ultrapassar a aprendizagem linear, pois a riqueza de materiais torna as possibilidades infinitas, tanto para o orientador do processo, quanto para o aluno. Quando os alunos são instigados pela busca de novas informações, o professor possibilita a reflexão, a transcendência e a emancipação. Desse modo, a EAD se denota como uma ferramenta valiosa para a otimização do processo de ensino aprendizagem e para a redução dos níveis de desigualdades das oportunidades escolares. Todos os processos de organizar o currículo, as metodologias, os tempos e espaços necessitam ser revisados e isso é complexo, indispensável e um tanto assustador, porque não há modelos prévios e bem-sucedidos para aprender.

Visando facilitar o processo de aprendizagem dos alunos, é importante que cada escola estabeleça um plano estratégico de como executar estas mudanças, por meio da capacitação de 
professores, coordenadores, e alunos para que possam atuar com metodologias ativas, com currículos mais flexíveis, com inversão de processos em que primeiro, atividades devem acontecer online e, depois em sala de aula. Pode ser se iniciar de forma mais pontual, apoiando professores, gestores e alunos que estão mais motivados e tem experiências em integrar o presencial e o virtual. É possível aprender com os que estão mais avançados e compartilhar esses projetos, atividades, resoluções.

Muitos pontos observados que reforçam as metodologias EAD são o surgimento de novas mídias dinâmicas, que estão provocando transformações no comportamento em todas as esferas da sociedade. As gerações mais jovens são as que assimilam mais rápido e se agregam a essas novas tecnologias em seu cotidiano. Se antigamente os alunos aprendiam apenas copiando conteúdos expostos no quadro-negro, não se pode esperar que os alunos do século XXI possam construir conhecimento fotografando a lousa. Uma oportunidade para se reinventar a sala de aula física é utilizar técnicas e metodologias desenvolvidas para uso em cursos online, misturando real e virtual.

Outro assunto merecedor de destaque é a questão da distância, que é um tema muito importante e um dos motivos de evasão nos cursos online, porque muitos alunos esbarram na falta de tempo ou na falta de dedicação necessária para realizar o curso a distância, o que exige um olhar atento por parte do professor tutor e um acompanhamento constante durante o processo. $\mathrm{O}$ entendimento por parte do aluno das demandas da aprendizagem a distância e o comprometimento com o processo online não são as únicas formas de determinar o sucesso num curso virtual, mas auxiliam na manutenção do envolvimento e do engajamento na EAD.

Estudos mais específicos procuram completar o conceito de interação dos alunos no sistema EAD, através da concepção dos indivíduos e seus respectivos estados de espírito; compreender fenômenos como a distância psicológica o isolamento, falta de relacionamento e sentimento.

\section{REFERÊNCIAS}

ALMEIDA, M.E.B. de; IANNONE, L.R.; SILVA, M.G.M da; VILLARINHOS, M.C.S. Educação a distância: oferta, características e tendências dos cursos de Licenciatura em Pedagogia. São Paulo: F.V.C., 2012.

BARRETO, Robério Pereira. Weblog e as práticas interacionais de escrita: web letramentos. 2014.

BATISTA, Erlinda Martins. O papel do fórum-online em um curso de pós-graduação Lato senso a distância: um estudo de caso. 2006.

BELLONI. Maria Luiza. Educação a Distância. Campinas: Autores Associados, 1999.

BRASIL. Decreto 5.622, de 19 de dezembro de 2005. Regulamenta o artigo 8o da Lei no 9.394, de 20 de dezembro de 1996, que estabelece as diretrizes e bases da educação nacional. Diário Oficial [da] 
República Federativa do Brasil. Brasília, DF, 20 dez. 2005. Disponível em: http://www.planalto.gov.br/ccivil_03/_Ato2004- 2006/2005/Decreto/ D5622.htm. Acesso em: I4 jan. 2021.

BRITO, M. S. S. Tecnologias para a EAD via internet. [19--?]. Disponível em:< http://www.lynn.pro.br/pdf/educatec/brito.pdf >. Acesso em: I2 jan. 2021.

CYRS, T. E.; CONWAY, E. D. Teaching at a distance with the mergin technologis: an instructional systems approach. Las Cruces: New México State University, 1997.

CRUZ, D. M.; BARCIA, R. M. Educação a distância por videoconferência. Tecnologia Educacional, v. 28, n. 150/151, jul./dez. 2000.

DE ALMEIDA, Maria Elizabeth Bianconcini. Educação a distância na internet: abordagens e contribuições dos ambientes digitais de aprendizagem. Educação e pesquisa, 2003, v. 29, n. 2, p. 327340.

DOS SANTOS, Davila dos Santos Davila; DE FREITAS, Ernani Cesar. Conhecimento em rede e a inteligência coletiva aplicada na ferramenta Scoop. it. Rizoma, v. 4, n. 2, p. 171-186, 2016.

DOS SANTOS, Wanessa Cristina Mendes. Papel do professor e do aluno na educação a distância. Caderno de Publicações, Univag, 2016.

FISCHER, G. S. Um ambiente virtual multimídia de ensino na web com transmissão ao vivo e interatividade. [Dissertação (Mestrado em Informática) 200o]. Universidade Federal do Rio Grande do Sul, Porto Alegre, 2000.

GATTI, Bernardete A. Reconhecimento social e as políticas de carreira docente na educação básica. Cadernos de pesquisa, 2013, v. 42, n. I45, p. 88-III.

GOMES, Maria João. Gerações de inovação tecnológica no ensino a distância. Revista Portuguesa de Educação, 2003.

MORAN, J. M. A distância e o presencial cada vez mais próximos. Disponível em: http://www.eca.usp.br/prof/moran/site/textos/educacao_online/proximos.pdf. Acesso em: i8 jan. 2021.

PEREIRA, Luís Miguel Cruz Simões. Co-construção de estratégias de ensino numa comunidade de prática online: análise de interações entre professores do Io ciclo do ensino básico. 2007 . [Dissertação de Mestrado]. Universidade de Aveiro.

ROMANI, L. A. S.; ROCHA, H. V. A complexa tarefa de educar a distância: uma reflexão sobre o processe educacional baseado na web. Revista Brasileira de Informática na Educação, Florianópolis, n. 8, p. 7i-8I, 200I.

SILVA, Marco. Educação online: teorias, práticas, legislação, formação corporativa. Edições Loyola, 2003.

TUCKMAN, B. A investigação qualitativa ou o estudo de caso. Manual de Investigação em Educação, 2005, p. 507-535. 